\title{
Masturbatory Behavior in a Population Sample of German Women
}

\author{
Andrea Burri, $\mathrm{PhD}^{1}$ and Ana Carvalheira, $\mathrm{PhD}^{2}$
}

\begin{abstract}
Background: Human masturbation is and has been a very heatedly and controversially discussed topic in human sexuality. Studies investigating aspects of human masturbatory behavior and female sexual pleasure remain scarce. This lack of knowledge opens the door to further controversies and misconceptions.

Aim: To conduct an explorative study on female masturbatory behavior to gain more insight into this nonreproductive sexual behavior and provide an empiric basis for future research.

Methods: A total of 425 German women (mean age 26.6 years), $61.4 \%$ of whom were in a committed relationship, completed a comprehensive 76-item online survey consisting of study-specific, self-constructed questions and validated and standardized questionnaires.
\end{abstract}

Main Outcome Measure: Correlation and comparative analyses were performed. Results are presented numerically as means and percentages.

Results: The majority (94.5\%) of women indicated having masturbated at least once in their life, with a mean age at first masturbation of 14 years. $85.9 \%$ of women described masturbation as "genital self-stimulation until reaching orgasm." The majority of women reported masturbating 2 or 3 times a week (26.8\%) or once a week $(26.3 \%)$. Factors independently associated with masturbation frequency were relationship status, orgasm frequency, openness to new experience, and body acceptance. Almost all women (91.5\%) reported masturbating also when in a relationship. For the 5.5\% of women who had never engaged in autoerotic stimulation, the 2 main reasons were "I hardly every feel sexual desire" and "sex is a partner-only thing." $7.6 \%$ reported never experiencing an orgasm during masturbation, whereas $50.3 \%$ indicated that they always reached orgasm during autostimulation. The reasons cited for engaging in masturbation were manifold, ranging from sexual desire to relaxation and stress reduction. The most common fantasy included the partner; however, $20.7 \%$ fantasized about being "defenseless," and $8.7 \%$ thought about a "disturbing" scenario that they chose not to elaborate further.

Clinical Implications: For many women, masturbation does not represent "a partner substitute" to seek sexual pleasure, but rather is a stress coping and relaxation strategy.

Strengths \& Limitations: This is one of the very first studies to provide more in-depth insight into a variety of aspects related to female masturbation. The representativeness of the data is limited to this particular sample of German women.

Conclusion: Our findings highlight the huge diversity in terms of masturbation frequency, motivations, styles, and preferences that can be observed in this particular population sample of German women. Burri A, Carvalheira A. Masturbatory Behavior in a Population Sample of German Women. J Sex Med 2019;16:963-974.

Copyright () 2019, International Society for Sexual Medicine. Published by Elsevier Inc. All rights reserved.

Key Words: Masturbation; Women; Sexual Function; Orgasm Ability

Received March 1, 2019. Accepted April 18, 2019.

Institute for Sex Counseling and Sexual Sciences, Zurich, Switzerland;

2ISPA University Institute of Psychological, Social and Life Sciences, Lisbon, Portugal

Copyright (c) 2019, International Society for Sexual Medicine. Published by Elsevier Inc. All rights reserved.

https://doi.org/10.1016/j.jsxm.2019.04.015

\section{INTRODUCTION}

Human masturbation is and has been a very heatedly and controversially discussed topic in human sexuality, and it was only by the mid-20th century, with the pioneering work of Alfred Kinsey, that masturbation was partially freed from its negative perception. ${ }^{1,2}$ In 1972, the American Medical Association consensually declared masturbation as "normal." ${ }^{3}$ In the past 30 years, masturbation even started to be viewed a health 
benefit, with evidence suggesting that masturbation improves sexual health. ${ }^{4-7}$ Still, the idea of masturbation as a beneficial strategy for a healthy sexual development has been met with silence and even apprehension across certain scientific and educational communities. For example, a recent study found that young people receive mixed messages about this autosexual behavior and learn about it predominantly through the media and peers and not through rational discourse in families and schools, emphasizing the reticence surrounding the subject. ${ }^{8}$

Also striking is the role of gender in the perception of the "legitimacy" of autostimulation. According to Kaestle and Allen, ${ }^{8}$ many women still struggle to accept masturbation as a "normal" nonreproductive sexual behavior, whereas most men recognize the beneficial aspects of masturbation for healthy sexual development. Not surprisingly, this differing view of the appropriateness of masturbation is reflected in the behavior itself. In a meta-analysis exploring multiple facets of human sexuality, Oliver and Hyde found gender differences to be most prominent in masturbation, with men masturbating much more frequently than women. These results are in line with other studies, such as the study conducted by Leitenberg et al, ${ }^{10}$ in which twice as many men as women had ever masturbated and the men masturbated 3 times more often than the women. ${ }^{10}$ It is not just masturbation frequency that differs by gender. Data reported by Hesselhund ${ }^{11}$ suggest that men use masturbation as a supplement for sexual intercourse, whereas women tend to use it as a substitute. However, other studies found masturbation and intercourse frequency to be more complementary for women and more compensatory for men. ${ }^{12}$

Apart from gender differences in masturbation frequency, studies exploring different aspects of masturbatory behavior, such as techniques and motivation, remain scarce. This lack of knowledge opens the door to further controversies and misconceptions, especially in terms of female masturbation. To fill in some of these gaps in scientific knowledge on masturbation behavior, an explorative study was conducted to provide more insight into this nonreproductive sexual behavior and to potentially provide an empiric basis for future research.

To achieve a better understanding of female masturbation, we analyzed several variables related to masturbation. The objectives were to explore the frequency of masturbation, factors associated with masturbation frequency, reasons for masturbating and for not engaging in masturbation, main fantasies/thoughts during masturbation, preferences, masturbation in the context of a relationship, differences in masturbatory behavior related to sexual orientation, and variables related to orgasm and first sexual activity.

\section{MATERIALS AND METHODS}

\section{Participants and Procedures}

A total of 425 women participated in an online survey on female masturbation and sexual functioning. The mean \pm SD age of the participants was $26.6 \pm 6.8$ years (range, $15-58$ years), and the majority (92.5\%) were premenopausal (Table 1). Most of women (61.4\%) were in a committed relationship, with an average relationship duration of 24 months. Participants reported a relatively high educational level, with an average of 15 years of education. A minority (4.7\%) suffered from a gynecologic disease, $6.8 \%$ from a medical condition, and $12.5 \%$ from a psychological condition (not further specified).

The survey, which consisted of 76 items in a combination of study-specific, self-constructed questions and validated and standardized questionnaires, was hosted on www.surveymonkey. com between July and September 2018. Because the survey was initiated in Germany, the online questionnaire was made available in the German language only. Advertisement and recruitment were done via distribution of the web link on specific survey platforms such as SurveyCircle and Thesius, via social networks (eg, Facebook) and university mailing lists, and through word-to-mouth recommendation. In the end, 528 women started the survey, and 425 (80.5\%) completed the entire questionnaire. The only inclusion criterion was being female. This was ascertained by the introductory text and informed consent, which mentioned that the survey was exclusively for women. All participants provided informed consent by checking a box before starting the online survey. The study received approval from the Institutional Review Board of the European Institute for Sexual Health.

\section{Measures}

Sociodemographic and other sample characteristics were obtained by asking participants about their age, menopausal status, educational level, gender(s) of sex partners, relationship status, duration of relationship, sexual orientation, and history of medical and psychological conditions.

\section{Masturbation-Related Variables}

To the best of our knowledge, currently there are no validated and standardized questionnaires that assess specific aspects related to masturbatory behavior. Consequently, we developed a studyspecific questionnaire that included items previously used in other studies investigating human masturbation, as well as questions specifically developed for this online survey. ${ }^{7,11,12}$ Masturbation-related variables were elaborated by the researchers and included items (if not indicated otherwise, a single question for each item was asked) asking whether the participant had ever masturbated; if yes, age at first genital stimulation and first masturbation; if no, reasons for not having engaged in masturbation; definition of masturbation; reasons for engaging in masturbation; fantasies during masturbation; abstinence from masturbation; masturbation styles and potential changes over the course of partner-less periods; preference of masturbation over partner stimulation and sexual intercourse; and masturbation while in a relationship. The majority of response options were framed as Likert-type scales or as list options with the possibility 
Table 1. Sample characteristics and variables related to orgasm and first sexual activity

\begin{tabular}{|c|c|c|}
\hline Variable & Value & $\mathrm{N}$ \\
\hline Age, $y r$, mean $\pm S D$ (range) & $26.59 \pm 6.77(15-58)$ & \\
\hline Education, yr, mean $\pm \mathrm{SD}$ (range) & $15.12 \pm 4.32(0-28)$ & \\
\hline Current relationship duration, mo, mean $\pm \mathrm{SD}$ (range) & $24.30 \pm 40.98(3-453)$ & \\
\hline Number of female sex partners, mean \pm SD (range) & $1.73 \pm 5.10(0-53)$ & \\
\hline Number of male sex partners, mean \pm SD (range) & $8.47 \pm 12.08(0-130)$ & \\
\hline Age at first sexual activity, yr, mean \pm SD (range) & $14.36 \pm 2.88(6-32)$ & 367 \\
\hline Age at first sexual intercourse, $y r$, mean \pm SD (range) & $17.09 \pm 2.89(10-33)$ & 362 \\
\hline Importance of sex, mean \pm SD (range) & $5.70 \pm 1.17(1-7)$ & 371 \\
\hline Importance of orgasm during sexual activity, mean \pm SD (range) & $4.63 \pm 1.49(1-7)$ & 371 \\
\hline Importance of orgasm during sexual intercourse, mean \pm SD (range) & $4.71 \pm 1.43(1-7)$ & 371 \\
\hline Orgasm frequency, mean \pm SD (range) & $3.91 \pm 1.49(1-6)$ & 371 \\
\hline Orgasmic function according to the FSFI, mean \pm SD (range) & $8.38 \pm 3.51(3-16)$ & 371 \\
\hline Orgasmic function according to the SCS-W, mean \pm SD (range) & $3.52 \pm 1.21(1-5)$ & 371 \\
\hline Orgasm-related distress according to the SCS-W, mean \pm SD (range) & $3.86 \pm 1.06(1-5)$ & 371 \\
\hline Satisfaction with orgasmic ability, mean \pm SD (range) & $5.05 \pm 1.72(1-7)$ & 371 \\
\hline Overall satisfaction with sex life, mean \pm SD (range) & $5.15 \pm 1.60(1-7)$ & 371 \\
\hline Marital status, n (\%) & & 425 \\
\hline Single & 156 (36.71) & \\
\hline In a relationship & $242(56.94)$ & \\
\hline Married & $23(5.41)$ & \\
\hline Divorced/separated & $4(0.94)$ & \\
\hline Menopausal status, n (\%) & & 425 \\
\hline Premenopause & 393 (92.47) & \\
\hline Perimenopause & $2(0.47)$ & \\
\hline Postmenopause & $7(1.65)$ & \\
\hline Surgical menopause & $1(0.24)$ & \\
\hline Don't know & $22(5.18)$ & \\
\hline Sexual orientation, $\mathrm{n}(\%)$ & & 425 \\
\hline Exclusively heterosexual & $282(66.35)$ & \\
\hline Predominantly heterosexual, only incidentally homosexual & $63(14.82)$ & \\
\hline Predominantly heterosexual but more than incidentally homosexual & $12(2.82)$ & \\
\hline Equally heterosexual and homosexual & $19(4.47)$ & \\
\hline Predominantly homosexual, only incidentally heterosexual & $11(2.59)$ & \\
\hline Predominantly homosexual but more than incidentally heterosexual & $11(2.59)$ & \\
\hline Exclusively homosexual & $27(6.35)$ & \\
\hline
\end{tabular}

FSFI = Female Sexual Function Index; SCS-W = Sexual Complaint Screener for Women.

to provide an "other, not listed" response. For "reasons for engaging in masturbation," a list option with 25 predefined reasons was provided with the additional option for "other, not listed," and participants were asked to indicate up to 5 reasons. Similarly, for "fantasies/thoughts during masturbation," 10 options in addition to "other not listed" were presented, and participants were asked to indicate up to 3 common fantasies/ thoughts. The participants were also asked a set of questions enquiring about the effects of masturbation on their sexual desire levels/sexual appetite, and subjectively perceived genital sensitivity (eg, "When I masturbate a lot I tend to have less desire to engage in sexual activities"; "When I masturbate a lot, I tend to have more desire to engage in sexual activities"; "When I masturbate a lot, my genitals become less sensitive"). Response options were on a 5-point Likert scale.
Frequency of masturbation was assessed with a single item asking "how often do you masturbate?," responded to on a 9-point Likert-type scale ranging from 1 (less than once a year) to 9 (several times a day).

\section{Sex and Orgasm-Related Variables}

Importance of sex and orgasm were assessed using single questions (eg, "how important is sex to you") with response options ranging from "not important at all" (1) to "very important" (7). Similarly, questions asking about satisfaction with orgasm ability and overall satisfaction with sex life could be responded to using a Likert-type scale that ranged from "not satisfied at all" (1) to "very satisfied" (7). Response scales for orgasm frequency during sexual intercourse and masturbation ranged from "never" (1) to "always" (6). 
Table 2. Masturbation-related variables

\begin{tabular}{|c|c|c|}
\hline Variable & Value & $\mathrm{N}$ \\
\hline $\begin{array}{l}\text { Age at first (not necessarily } \\
\text { sexual) genital stimulation, } \\
\text { yr, mean } \pm \text { SD (range) }\end{array}$ & $10.85 \pm 3.91(3-31)$ & 327 \\
\hline $\begin{array}{l}\text { Age at first masturbation, yr, } \\
\text { mean } \pm \text { SD (range) }\end{array}$ & $14 \pm 3.69(5-35)$ & 383 \\
\hline $\begin{array}{l}\text { What is masturbation for you?, } \\
n(\%)\end{array}$ & & 424 \\
\hline $\begin{array}{l}\text { Genital self-stimulation until } \\
\text { reaching orgasm }\end{array}$ & $364(85.85)$ & \\
\hline $\begin{array}{l}\text { Genital self-stimulation } \\
\text { without orgasm }\end{array}$ & $229(54.01)$ & \\
\hline $\begin{array}{l}\text { Caressing entire body } \\
\text { including genitals }\end{array}$ & $183(43.16)$ & \\
\hline $\begin{array}{l}\text { Caressing entire body } \\
\text { excluding genitals }\end{array}$ & $10(2.36)$ & \\
\hline $\begin{array}{l}\text { Caressing entire body } \\
\text { excluding genitals and } \\
\text { breasts }\end{array}$ & $9(2.12)$ & \\
\hline $\begin{array}{l}\text { Have you ever masturbated?, n } \\
\text { (\%) }\end{array}$ & & 414 \\
\hline Yes & 391 (94.45) & \\
\hline No & $23(5.55)$ & \\
\hline $\begin{array}{l}\text { If not, reason for not doing it ( } 5 \\
\text { most frequent), } n(\%)\end{array}$ & & 23 \\
\hline $\begin{array}{l}\text { “I hardly ever feel sexual } \\
\text { desire" }\end{array}$ & $7(30.5)$ & \\
\hline $\begin{array}{l}\text { "Sex is a partner-only thing/ } \\
\text { experience" }\end{array}$ & $7(30.5)$ & \\
\hline $\begin{array}{l}\text { "I don't like touching } \\
\text { myself" }\end{array}$ & $6(27.1)$ & \\
\hline $\begin{array}{l}\text { “I just never thought about } \\
\text { doing it” }\end{array}$ & $6(27.1)$ & \\
\hline "I don't know how to do it" & $6(27.1)$ & \\
\hline $\begin{array}{l}\text { Are you currently } \\
\text { masturbating?, n (\%) }\end{array}$ & & 368 \\
\hline Yes & 313 (85.05) & \\
\hline No & 55 (14.95) & \\
\hline $\begin{array}{l}\text { Was there a period in life } \\
\text { (longer than } 6 \text { mo) that } \\
\text { you did not masturbate?, n } \\
\text { (\%) }\end{array}$ & & 371 \\
\hline Yes & $97(26.15)$ & \\
\hline No & $241(64.96)$ & \\
\hline More than once & 33 (8.89) & \\
\hline $\begin{array}{l}\text { Has your masturbation style } \\
\text { changed over the years?, n } \\
\text { (\%) }\end{array}$ & & 361 \\
\hline Yes & 143 (39.61) & \\
\hline No & $171(47.47)$ & \\
\hline I don't know & $47(13.02)$ & \\
\hline
\end{tabular}

Table 2. Continued

\begin{tabular}{lll}
\hline Variable & Value & N \\
\hline $\begin{array}{l}\text { Has your masturbation style } \\
\text { changed during onger } \\
\text { partner-less periods?, n }\end{array}$ & 352
\end{tabular}

(\%)

$\begin{array}{lr}\text { Yes } & 118(22.52) \\ \text { No } & 183(51.99) \\ \text { I don't know } & 51(14.49)\end{array}$

Do you prefer to masturbate or

to be manually stimulated

by your partner?, n (\%)

Masturbation

68 (18.78)

Partner stimulation

$113(31.22)$

Sometimes masturbation,

170 (46.96)

sometimes partner

stimulation

Doesn't matter

11 (3.04)

Do you prefer to masturbate or

to be orally stimulated by

your partner?, n (\%)

Masturbation

77 (21.10)

Partner stimulation

148 (40.55)

Sometimes masturbation,

128 (35.07)

sometimes partner

stimulation

Doesn't matter

12 (3.29)

Do you prefer to masturbate or vaginal penetration?, $\mathrm{n}(\%)$

Masturbation

Penetration

195 (53.72)

Sometimes masturbation, sometimes penetration

128 (35.26)

Doesn't matter

$9(2.48)$

Do you think you masturbate

369

more or less than the

average woman of your

age?, n [\%]

More

111 (30.08)

Less

101 (27.37)

On average the same

157 (42.55)

Do you always use the same masturbation style?, n [\%]

Yes

242 (66.30)

No

123 (33.70)

What position do you masturbate in?, n (\%)

Lying on my tummy

65 (17.71)

Lying on my back

281 (76.57)

Sitting

$16(4.36)$

Standing

$5(1.36)$ 
Table 2. Continued

\begin{tabular}{|c|c|c|}
\hline Variable & Value & $\mathrm{N}$ \\
\hline $\begin{array}{l}\text { Do you also masturbate when } \\
\text { you are in a relationship?, } \mathrm{n} \\
\text { (\%) }\end{array}$ & & 354 \\
\hline Yes & 324 (91.53) & \\
\hline No & $30(8.47)$ & \\
\hline $\begin{array}{l}\text { If yes, do you masturbate more } \\
\text { or less frequently in a } \\
\text { relationship compared to } \\
\text { when you are single?, } \mathrm{n} \\
\text { (\%) }\end{array}$ & & 329 \\
\hline Much more frequently & $5(1.52)$ & \\
\hline Slightly more frequently & 24 (7.29) & \\
\hline Equally & 78 (23.71) & \\
\hline Slightly less frequently & $148(44.98)$ & \\
\hline Much less frequently & 74 (22.49) & \\
\hline $\begin{array}{l}\text { If yes, do you masturbate only } \\
\text { when you are sexually } \\
\text { dissatisfied or also when } \\
\text { you are satisfied?, n (\%) }\end{array}$ & & 330 \\
\hline Only when dissatisfied & 31 (9.39) & \\
\hline Also when satisfied & 280 (84.85) & \\
\hline Don't know & $19(5.76)$ & \\
\hline
\end{tabular}

Orgasmic response was measured using the corresponding item of the Sexual Complaint Screener for Women (SCS-W). ${ }^{13,14}$ The SCS-W is a sex-specific screening tool estimating female sexual complaints over the previous 6 months. The German version of the scale was recently validated. ${ }^{15}$ Along with the SCS$\mathrm{W}$, the Orgasm subscale of the German version of the Female Sexual Function Index (FSFI) was also used. ${ }^{16,17}$ The FSFI is a 19-item measure that allows a multidimensional assessment of women's sexual response. Response options are on a Likert-type scale ranging from 0 to 5 . Good psychometric properties have been reported for the German version of the FSFI. ${ }^{17}$ Cronbach's $\alpha$ value for the FSFI orgasm subscale in our study was 0.79 . For both items, a higher score means less problems and less distress with orgasmic function.

\section{Relationship Quality and Satisfaction}

These factors were assessed using the German version of the Relationship Assessment Scale. ${ }^{18,19}$ Response options for the 7 items are on a 5-point Likert-type scale ranging from 1 (low satisfaction) to 5 (high satisfaction). Studies have shown good psychometric properties for both the original English version and the German version of the scale. ${ }^{18,19}$ The Cronbach $\alpha$ value was 0.87 .

\section{Personality Dimensions}

Personality dimensions were assessed using the German version of the Ten Item Personality Index (TIPI). ${ }^{20,21}$ This scale is a 10-item measure of the Big Five dimensions-extroversion, agreeableness, conscientiousness, emotional stability and openness to experiences-designed to quickly assess the different personality dimensions with optimized validity. ${ }^{20}$ Response options are on a 7-point Likert scale ranging from "disagree strongly" (1) to "agree strongly" (7). Both the original English and translated German versions have shown good psychometric properties. ${ }^{20,21}$ Cronbach's $\alpha$ values were 0.76 for extraversion, 0.72 for emotional stability, 0.69 for agreeableness, 0.68 for conscientiousness, and 0.57 for openness to new experience.

\section{Body Image}

Body image was assessed using the Dresden Body Image Questionnaire. ${ }^{22}$ The Dresden Body Image Questionnaire is a 35-item German scale consisting of 5 subscales: body acceptance (eg, "I wish I had a different body"), vitality (eg, "I am physically fit"), physical contact (eg, "I do not like people touching me"), sexual fulfilment (eg, "I am very satisfied with my sexual experiences"), and self-aggrandizement (eg, "I use my body to attract attention"). Level of agreement is scored on a 5-point Likert scale, with higher scores indicating a more positive body image. Cronbach's alpha values were 0.77 for self-aggrandizement, 0.77 for body acceptance, 0.79 for physical contact, 0.88 for vitality, and 0.89 for sexual fulfilment.

\section{Statistical Analyses}

Data handling and statistical analyses were done using Excel (Microsoft, Redmond, WA, USA) and Stata 10 (StataCorp, College Station, TX, USA). Deviations from normal distribution were tested with the Kolmogorov-Smirnov test and the Shapiro-Wilk test. Because many of the continuous variables showed deviations from normal distribution (kurtosis and skewness), nonparametric statistical methods were chosen for all statistical analyses. Missing items were not imputed, but instead analyses were conducted on the available sample, and deviations from the overall sample size are indicated in all results and tables. To investigate the relationships between age and various variables, a set of correlation analyses were conducted, including a point biserial correlation coefficient, $r_{p b}$, for age and binary variables and Spearman correlation, $\rho$, for age and categorical and continuous variables. To explore patterns of associations between masturbation frequency and a set of potential "predictor" variables, linear regression analyses were conducted using masturbation frequency as the dependent variable. A stepwise forward approach was chosen consisting of 3 models, with model A capturing the contribution of sociodemographic characteristics, model B capturing the effects of sexual variables, and finally model C capturing the effects of psychoaffective variables. Comparisons between single women and partnered women and between heterosexual men and homosexual women were done using the Mann-Whitney $U$ test for continuous measures and the $\chi^{2}$ test for categorical and dichotomous measures. For all 


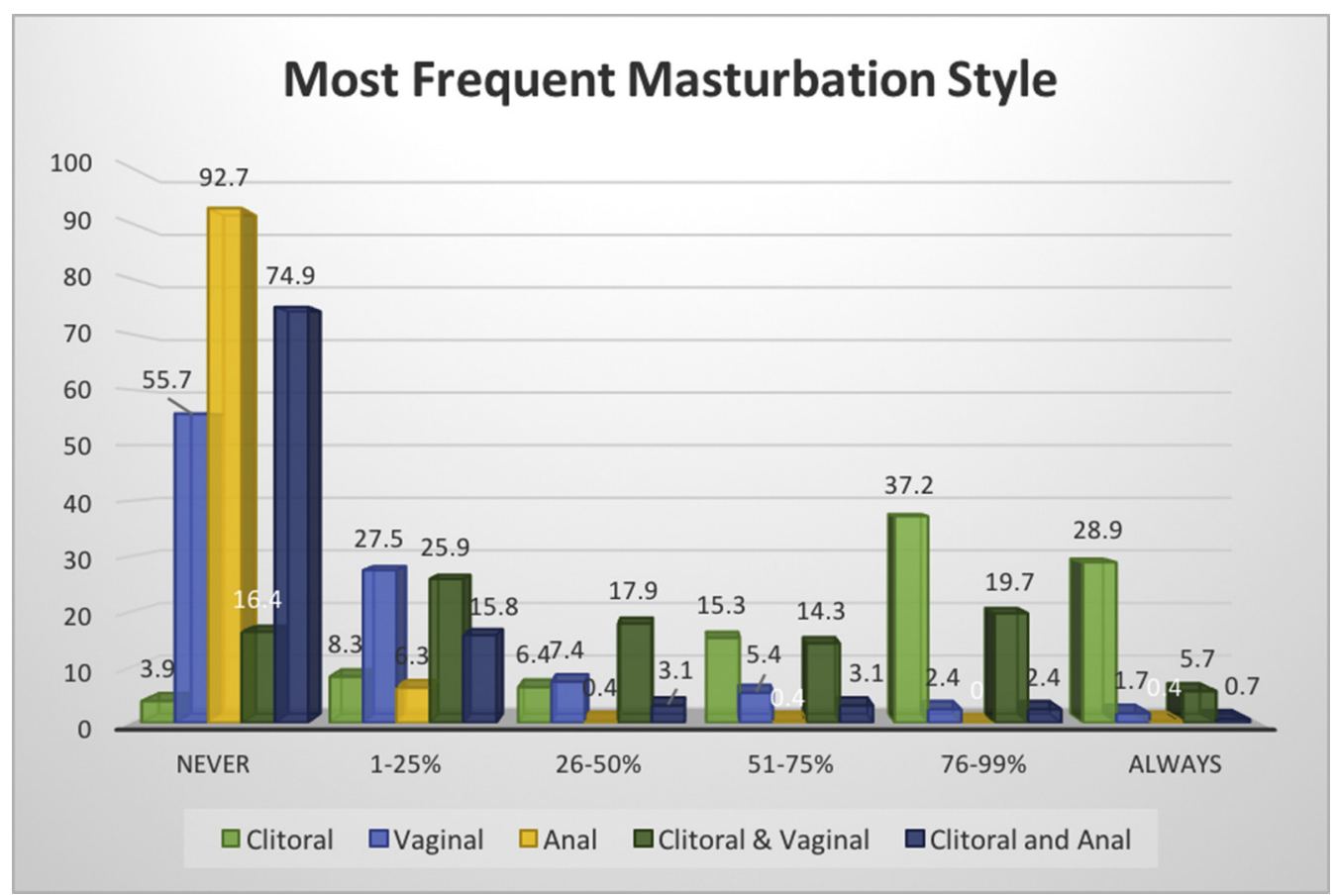

Figure 1. Different masturbation styles and reported frequencies. Figure 1 is available in color online at www.jsm.jsexmed.org.

analyses, a $P$ value $<.05$ was considered statistically significant, unless stated otherwise.

\section{RESULTS}

\section{Masturbatory Behavior}

Sociodemographic and sexual characteristics of the sample are presented in Table 1. A large majority (94.5\%) of women reported having masturbated at least once in their lives, and $85.1 \%$ reported doing so at the time of the survey (Table 2). The mean age at first genital stimulation (ie, not necessarily sexual stimulation but touching the genitals playfully without sexual motivation) was 10.9 years, and mean age at first masturbation was $14 \pm 3.7$ years (range, $5-35$ years; Table 2). For the $5.5 \%$ of women who had never engaged in autoerotic stimulation, the 2 main reasons cited were "I hardly every feel sexual desire" and "sex is a partner-only thing/ experience" (Table 2). More than one-quarter (26.2\%) reported having had periods of 6 months and longer in their lives when they did not masturbate; $8.9 \%$ said that they had more than 1 such episode (Table 2). Interestingly, 7.6\% reported never experiencing orgasm during masturbation, whereas $50.3 \%$ reported always reaching orgasm during masturbation. A significantly larger proportion $(73.8 \%)$ wished they could always achieve orgasm.

Although the majority of women preferred partner stimulation over masturbation $(31.2 \%$ for manual stimulation, $40.6 \%$ for oral stimulation, and $53.7 \%$ for vaginal penetration), $18.8 \%$ of women indicated preferring masturbation over manual partner stimulation, $21.1 \%$ over oral stimulation, and $8.5 \%$ over vaginal penetration (Table 2). Only a small percentage reported no preference.
The various masturbation styles and their reported frequencies are shown in Figure 1. Clitoral and combined clitoral and vaginal stimulation were the most commonly applied techniques, and anal stimulation (alone or in combination) was less frequently performed. Two-thirds (66.3\%) of the women reported always using the same masturbation style, 39.6\% reported that their masturbation style changed over the years, and $22.5 \%$ said it did so over the course of longer partnerless periods (Table 2). The most frequent position was lying on the back $(76.6 \%)$, yet $1.4 \%$ reported masturbating while standing.

\section{Reasons for Engaging in Masturbation and Fantasies/Thoughts During Masturbation}

The 5 main reasons for engaging in masturbation were feelings of sexual desire $(75.6 \%)$ and for sexual satisfaction $(69.4 \%) .44 \%$ reported masturbating for relaxation, $22.6 \%$ for stress reduction, $22.6 \%$ because they liked touching themselves, and $25.4 \%$ for no particular reason (Table 3). $41.9 \%$ of the women fantasized about their partner, $31.5 \%$ fantasized about a male stranger, $27.3 \%$ fantasized about a known male, and $20.7 \%$ fantasized about being "defenseless and overpowered" (Table 3). 9.2\% fantasized about group sex, and $8.7 \%$ thought about a "disturbing" scenario that they chose not to elaborate on further.

\section{Variables Associated with Masturbation Frequency}

A broad range of masturbation frequency was reported, a broad range could be observed with the majority of women reporting masturbating $2-3$ times a week $(26.8 \%)$ or once a week $(26.3 \%)$, whereas $2.4 \%$ reported doing it several times a day and $2.9 \%$ reported doing it less than once a year (Figure 2). 
Table 3. Main reasons for masturbating and main fantasies/thoughts during masturbation in the total sample

\begin{tabular}{|c|c|c|c|c|c|}
\hline Reasons for masturbating & $\mathrm{N}$ & $\%$ & Fantasies/thoughts & $\mathrm{n}$ & $\%$ \\
\hline Sexual satisfaction & 295 & 69.41 & Partner & 178 & 41.88 \\
\hline When I feel sexual desire & 317 & 74.59 & $\begin{array}{l}\text { Sex with a known male } \\
\text { (that you haven't been intimate with before) }\end{array}$ & 116 & 27.29 \\
\hline To relax & 187 & 44.00 & $\begin{array}{l}\text { Sex with a known female } \\
\text { (that you haven't been intimate with before) }\end{array}$ & 39 & 9.18 \\
\hline To become tired before falling asleep & 93 & 21.88 & Sex with a male stranger & 134 & 31.53 \\
\hline To offload & 62 & 14.59 & Sex with a female stranger & 57 & 13.41 \\
\hline To reduce stress & 96 & 22.59 & Group sex & 73 & 17.18 \\
\hline To feel feminine & 32 & 7.53 & To be tied up/bondage & 90 & 21.18 \\
\hline To feel sexy & 47 & 11.06 & To have the eyes covered & 39 & 9.18 \\
\hline To feel myself & 83 & 19.53 & To be "defenseless/overpowered" & 88 & 20.71 \\
\hline Because I like touching myself & 96 & 22.59 & A "disturbing" scenario that I'd rather not disclose & 37 & 8.71 \\
\hline When I am bored & 70 & 16.47 & & & \\
\hline To distract myself & 34 & 8.00 & & & \\
\hline Because my partner is not touching me & 21 & 4.94 & & & \\
\hline When I am frustrated/depressed & 24 & 5.65 & & & \\
\hline When I am excited/nervous & 18 & 4.24 & & & \\
\hline When I don't feel loved & 9 & 2.12 & & & \\
\hline When I am happy & 56 & 13.18 & & & \\
\hline When I am hungry & 3 & 0.71 & & & \\
\hline When I am sad & 8 & 1.88 & & & \\
\hline To kill time & 46 & 10.82 & & & \\
\hline When I am tense & 41 & 9.65 & & & \\
\hline When I am drunk & 22 & 5.18 & & & \\
\hline After consuming drugs & 12 & 2.82 & & & \\
\hline When I am euphoric & 20 & 4.71 & & & \\
\hline For no real reason/just like that & 108 & 25.41 & & & \\
\hline
\end{tabular}

Stepwise regression modeling indicated relationship status (single vs in a partnership; $\left.r_{p b}=0.488 ; P<.05\right)$, orgasm frequency $\left(r_{p b}=0.14 ; P<.05\right)$, openness to new experience $\left(r_{p b}=0.16 ; P\right.$ $<.05)$, and body acceptance $\left(r_{p b}=0.03 ; P<.05\right)$ to be independently associated with reported masturbation frequency (Table 4).

\section{Masturbation in the Context of a Relationship}

A large majority (91.5\%) of the women reported masturbating also when in a relationship. More than one-half of the women $(66.5 \%)$ reported masturbating less frequently when in a relationship, and only $8.8 \%$ reported masturbating more frequently when in a relationship. Almost one-quarter (24\%) of the women reported masturbation frequency independent of their relationship status. A small percentage of women (9.4\%) reported masturbating only when they were dissatisfied with the relationship, in contrast to $84.9 \%$ who reported masturbating also when they were satisfied (Table 2). Single women masturbated significantly more often compared to partnered women $(z$-score $=4.2 ; P<.001)$. Overall, single women more frequently preferred masturbation over partner stimulation, whereas it was the opposite for partnered women. Overall, partnered women reported greater overall satisfaction with their sex life compared with single women $(z$-score; $P<.001)$

In terms of reasons to engage in masturbation, the only significant difference was found in the response "to feel sexy," with single women indicating this reason more often than partnered women $\left(\chi^{2}=4.2 ; P<.05\right)$. Having sex with a known male $\left(\chi^{2}=38.3 ; P<.001\right)$ a known female $\left(\chi^{2}=4.9 ; P<.05\right)$, or a male stranger $\left(\chi^{2}=4.4 ; P<.05\right)$ were masturbation fantasies significantly more common in single women compared with partnered women, whereas partnered women more frequently reported thinking of a situation in which they felt "defenseless/ overpowered" $\left(\chi^{2}=4.9 ; P<.05\right)$ (data not shown).

\section{Age-Dependent Differences in Sexual and Masturbatory Behavior}

Older women had their first sexual intercourse experience at a later age compared with younger women, but this finding was not replicated for first sexual activity $(\mathrm{r}=0.11 ; P<0.05)$. Older women were more likely than younger women to consider experiencing orgasm during sexual intercourse to be important $(r=0.16 ; P<.001)$. In terms of sexual functioning, compared with younger women, older women reported less orgasm 


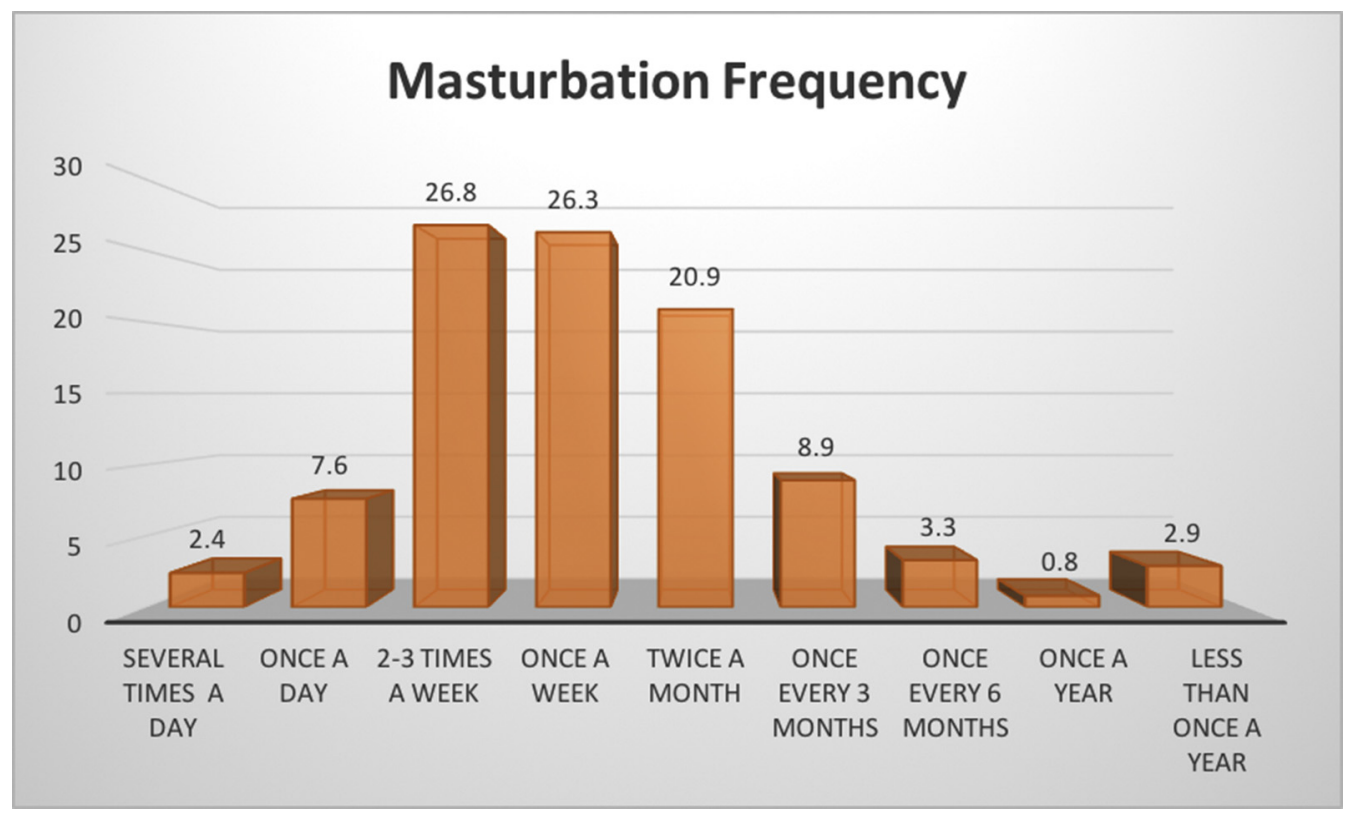

Figure 2. Masturbation frequency (defined as in the past 12 months) as reported by the 391 women who indicated ever having masturbated. Figure 2 is available in color online at www.jsm.jsexmed.org.

problems (as assessed by the FSFI and SCS-W; $r=0.16$ and 0.14, respectively: $P<.005$ for both) and greater satisfaction with their orgasmic ability $(r=0.13 ; P<.01)$. In contrast, they reported being less satisfied with their overall sex life $(r=-0.20$; $P<.001)$.

No age-dependent differences in the most commonly reported masturbation styles could be detected. Similarly, older women did not differ from younger women in terms of the reasons why they masturbated. However, an effect of age was seen for thoughts/fantasies during masturbation, with younger women more often fantasizing about their partner $\left(\chi^{2}=11.1\right.$; $P=.0008)$ compared with older women, who reported more often fantasizing about an unknown male $\left(\chi^{2}=4.05 ; P=.044\right)$ or female $\left(\chi^{2}=5.36 ; P=.020\right)$ (data not shown).

\section{DISCUSSION}

Masturbation remains a highly stigmatized topic, perpetuating the silence and myths surrounding this autoerotic behavior. ${ }^{23}$ This is particularly worrisome given that much evidence points to the substantial positive impact of masturbation on people's overall mental, physical, and sexual health, as well as on the sexual development of young adolescents. ${ }^{5-8}$ The aim of the present study was to explore the multiple facets and functions of masturbation to provide more comprehensive knowledge and to improve our understanding of this behavior.

\section{Frequency of Masturbation}

Our present findings show a high frequency of masturbation in this sample of 15- to 58-year-old German women age and as such contradicts previous studies indicating that a much smaller proportion of women masturbate compared with men. ${ }^{10}$ In our sample, $94.5 \%$ of the women reported having masturbated at least once in their lives. Whereas our findings are comparable to the results reported by Carvalheira and Leal, ${ }^{7}$ with $91 \%$ of their female Portuguese sample (with a similar mean age) masturbating at some point in their lives, other studies, such as the one by Gerressu et $\mathrm{al}^{12}(71.2 \%)$, have reported a lower prevalence. In terms of masturbation at the time of the study, $85.1 \%$ of women in our study reported currently masturbating, compared with $63 \%$ in the study of Carvalheira and Leal ${ }^{7}$ and $42 \%$ in the study of Gerrescu et al. ${ }^{12}$ Moreover, the small percentage (5.5\%) of women who reported never having masturbated stands in contrast to the $40 \%$ found in a Croatian study of 410 women. ${ }^{24}$ This significant difference might be due to methodological differences in data assessment or to sociocultural differences. In contrast to the face-to-face interviews conducted by Ba'cak, ${ }^{24}$ we used an online platform for data collection, which is a more reliable way for participants to provide truthful information on such sensitive topics as sexual behaviors compared with paper and pencil questionnaires. ${ }^{7,24}$ It is also possible that cultural views on masturbation differ between the 2 countries, and that there is less inhibition, guilt, and shame regarding masturbatory behavior in Germany than in Croatia.

\section{Reasons for Not Masturbating}

The 2 most commonly cited reasons for not engaging in masturbation were "I hardly ever feel sexual desire" and "sex is a partner-only thing/experience." It is possible that the former reason may be reported by a small minority of asexual women who have very low or absent interest in sexual activities, whereas the latter reason might be colored by religious beliefs about 
Table 4. Sociodemographic, sexual, and psychoaffective factors associated with masturbation frequency $(N=369)$

\begin{tabular}{|c|c|c|c|}
\hline Factor & Model A & Model B & Model C \\
\hline \multicolumn{4}{|l|}{ Sociodemographic variables } \\
\hline Age & $-0.008(-0.017$ to 0.035$)$ & $-0.015(-0.012$ to 0.043$)$ & $-0.026(-0.043$ to 0.026$)$ \\
\hline Education & $0.013(-0.052$ to 0.025$)$ & $0.012(-0.051$ to 0.026$)$ & $0.021(-0.012$ to 0.039$)$ \\
\hline $\begin{array}{l}\text { Relationship status } \\
\text { (partnered vs single) }\end{array}$ & $0.488(-0.895 \text { to }-0.081)^{*}$ & $0.638(0.088-1.188)$ & $0.639(-0.065$ to -0.982$)$ \\
\hline Relationship duration & $0.001(-0.005$ to 0.004$)$ & $0.001(-0.005$ to 0.004$)$ & $0.001(-0.001$ to 0.003$)$ \\
\hline \multicolumn{4}{|l|}{ Sexual variables } \\
\hline Age at first sexual intercourse & & $-0.045(-0.108$ to 0.017$)$ & $-0.051(-0.1192171$ to 0.017$)$ \\
\hline Orgasm frequency & & 0.135 (0.017 to -0.276$)^{*}$ & 0.176 (0.097-0.256) \\
\hline Satisfaction with sex life & & $0.082(-0.037$ to 0.203$)$ & $0.031(-0.092$ to 0.156$)$ \\
\hline \multicolumn{4}{|l|}{ Psychoaffective variables } \\
\hline Openness to new experience & & & 0.158 (0.038-0.279)* \\
\hline Extraversion & & & $0.065(-0.070$ to 0.200$)$ \\
\hline Agreeableness & & & $0.005(-0.137$ to 0.149$)$ \\
\hline Emotional stability & & & $-0.101(-0.234$ to 0.032$)$ \\
\hline Conscientiousness & & & $-0.072(-0.176$ to 0.032$)$ \\
\hline Body acceptance & & & $0.031(0.002-0.059)^{*}$ \\
\hline Cox and Snell $R^{2}$ & 0.03 & 0.07 & 0.14 \\
\hline $\begin{array}{l}\text { Breusch-Pagan test for } \\
\text { heteroscedasticity }\end{array}$ & 0.08 & 3.50 & 24.31 \\
\hline$P$ value & .772 & .061 & .000 \\
\hline
\end{tabular}

${ }^{*} P<.05$.

marriage and sex or by a more reproductive-based view of sexuality. Other common reasons included "I don't like touching myself" and "I don't know how to do it." Whereas a negative body image and feelings of discomfort in their own body-maybe even to the point of aversion-might be a reason for some women to never engage in masturbation, other have reported a lack information on how to do it and/or little curiosity to explore their own body. Overall, it would have been interesting to compare the cultural and religious background of these women, but unfortunately this information was not available.

\section{Reasons to Engage in Masturbation and Related Fantasies}

Overall, 25 different reasons for masturbating were mentioned by the women in this study; however, this list may not be absolute. The 4 most commonly reported reasons for engaging in masturbation were sexual desire, sexual satisfaction, relaxation, and stress reduction. In addition, approximately one-quarter of the women reported no particular reason for masturbating. An interesting difference was observed for "feeling sexy," which was more often reported by single women compared to partnered women. While contrasting with the specific motivations by other studies, our findings support the overall trend of women masturbating for a multitude of reasons, far from being solely sexually motivated. ${ }^{7}$ Masturbation is still frequently regarded as a sexual partner substitute, but results from our study and other studies indicate that apart from provided another avenue for women to experience sexual pleasure, it also serves other purposes, such as stress coping and relaxation. , 11,12 This may be one reason to explain the health benefits of masturbation. Not only can masturbation positively influence physical well-being via a multitude of released hormones (including oxytocin, which has been known to have stress-buffering effects by reducing cortisol), but it can also exert a positive impact on a woman's psychoaffective state by helping her cope with stress and distress. ${ }^{25,26}$ Women across many cultures and countries could benefit from the knowledge that in many women, masturbation is not solely for sexual pleasure, which might help destigmatize views on this autoerotic behavior.

A similar diversity was found regarding sexual fantasies. Although fantasies involving the current partner were the most common scenario, women also frequently fantasized about either a known male or an unknown male. In addition, almost $10 \%$ of the women fantasized about group sex or a "disturbing scenario" that they chose not to elaborate further. Again, these findings speak against the theory of masturbation as solely a partner substitute. ${ }^{11}$ This is supported by the fact that approximately $10 \%$ of women reported masturbating more frequently while in a relationship and $25 \%$ stated that the frequency did not depend on the relationship status.

\section{Masturbation Styles and Preferences}

Diversity and variety were also found in terms of masturbation styles and preferences. Overall, clitoral and combined clitoral and vaginal stimulation was the most commonly applied style, whereas anal stimulation (alone or in combination) was less 
frequently performed. Clearly, there are a multitude of different forms from which to gain pleasure, and these are different for every woman. However, despite that diversity, only one-half of the women reported preferring vaginal penetration, supporting the idea than men place a higher value on vaginal penetration as a sexual activity. ${ }^{27}$

\section{Frequency of Masturbation and Associated Variables}

The frequency at which women masturbate ranges widely. Most of the women in our study reported masturbating either 2 or 3 times a week or once a week. In general, the frequency figures do not match the findings of Carvalheira and Leal, ${ }^{7}$ who found that the majority of their women masturbated less than once a month $(34 \%)$, only $14.3 \%$ did it more than once a month, and only $9.8 \%$ did it weekly. These differences are not likely related to demographic characteristics, given the comparable mean age in the 2 samples (29.4 vs 26.6 years) and the similar percentage of single women $(55.6 \%$ vs $56.9 \%)$. It remains to be seen whether sociocultural or religious factors might help explain the discrepancy in masturbation frequency between the 2 studies, given that a substantial proportion of women in the study by Carvalheira and Leal ${ }^{7}$ reported feelings of shame and guilt related to masturbation, which was not the case in our study population.

Interestingly, we also found quite a substantial number of women who reported masturbating once a day and $2.4 \%$ reporting doing it several times a day. It has been suggested that some individuals use sex as a mood regulator in times of heightened stress and pressure. ${ }^{28}$ Indeed, post hoc analyses of the women reporting masturbating daily or more than once a day found that they were more likely to report doing so to relieve stress.

Although our results reflect the frequency of masturbation at the time of the study, the fact that approximately one-quarter of the women reported no masturbating for periods of 6 months and longer shows that masturbatory patterns can and do change over the lifespan. Although we did not assess the reasons why these women stopped masturbating for an extended period, such factors as a change in relationship status, motherhood, periods of more/less stress, and others might be involved.

Furthermore, we found several factors independently associated with the frequency of masturbation. Single women, higher orgasm frequency during masturbation, openness to new experiences, and greater body acceptance were all more likely to be associated with a higher masturbation frequency in the previous 12 months. It has been argued that orgasm may act as a reward for women to engage in sexual behavior by activating brain regions implicated in reward, pleasure, and addiction. ${ }^{29}$ Alternatively, orgasm also has been suggested to be a secondary reinforcer, with sexual arousal seen as the primary reward for sexual activity, and orgasm is associated with sexual arousal with the partner. ${ }^{30}$ It is possible that orgasm acts as a reward also in the context of autostimulation, even in the absence of reproductive opportunities; however, as mentioned earlier, sexual pleasure and reward do not seem to be the only reasons why women engage in masturbation.

In terms of personality characteristics, being open to new experiences was associated with masturbation frequency and was linked to coital orgasm frequency. ${ }^{31}$ Similarly, the concept of a positive body image has been repeatedly found to be associated with a pleasurable sex life, greater sexual satisfaction, and more confidence when sexually interacting with a partner. ${ }^{32}$ It seems that these associations persist even in the absence of a partner, and that negative emotions and cognitions related to body might be a reason why the women are not engaging in or enjoying selfstimulation.

Overall the variables only explain little of the variance, indicating that other factors might influence masturbation frequency. Indeed, a recent study by Randolph et $\mathrm{a}^{33}$ found a positive association between masturbation and testosterone, as well as a negative association with follicle-stimulating hormone. ${ }^{33}$ Most likely, sexual desire acts as a mediator in the relationship between hormones and masturbation frequency.

\section{Study Strengths and Limitations}

To the best of our knowledge, this is the first study providing an in-depth exploration of women's masturbatory behavior. Considering the length and sensitive nature of the survey, the sample size of 425 women is very respectable, thus the study can be viewed an important scientific contribution to the current knowledge of women's autoerotic behavior. In addition, the online format can be considered a strength because it allows for a high degree of anonymity, reducing potential bias arising from social desirability.

Nonetheless, several limitations of the study should be mentioned. First, various sample characteristics, such as education, culture/religion, and/or age, might have limited the generalizability of our results. Thus, our findings should be considered specific to this sample of German women aged 15-58 years and should not be extrapolated to other populations. Although we believe that our results merit reporting, we demand caution when interpreting the results-which, however, does not invalidate these particular findings. Also, various biases, such as volunteer bias (a common problem encountered in sex research), could have been present and have affected the results. Studies have shown that individuals participating in surveys and studies of a sexual nature tend to be more sexually experienced and to hold less traditional view on sexuality. ${ }^{34}$ This could be reflected in an overestimation of the percentage of women who indicated ever having masturbated. Furthermore, we had no information on our participants' phase of the menstrual cycle or use of hormonal contraception, which could have affected sexual desire level and thus the frequency of masturbation. Finally, the main questionnaire was developed specifically for this survey and does not rely on validated or standardized instruments, given the 
current lack of such questionnaires on masturbatory behavior. This should represent a limitation only when future comparative analyses are envisaged, however.

\section{CONCLUSION}

Our findings underscore the huge diversity in terms of masturbation frequency, motivations, styles, and preferences observed in this sample of German women. Of particular note is the fact that for many women, masturbation does not represent "a partner substitute" to seek sexual pleasure, but rather represents a stress coping and relaxation strategy. Clearly, sexual pleasure is a unique experience, whether in solo mode or with a partner.

In terms of clinical implications, the present study highlights important topics related to masturbation that need to be addressed and discussed with female patients seeking help to overcome sexual difficulties. These include, for example, dysfunctional sexual believes related to masturbation, negative thoughts and emotions such as shame and guilt associated with masturbation, and the role of masturbation as a diverse form of pleasure and not a substitute in the context of a stable relationship. While not invalidating our findings, the limited representativeness of the sample demands caution when interpreting the results.

Corresponding Author: Andrea Burri, PhD, Institute for Sex Counselling and Sexual Sciences, Alte Landstrasse 77, 8706 Meilen, Switzerland. Tel: +41767768294; Fax: +4940351117; E-mail: andrea.burri@kcl.ac.uk

Conflicts of interest: A.B. serves as an advisor and consultant for A. Menarini Pharmaceuticals.

Funding: None.

\section{STATEMENT OF AUTHORSHIP}

\section{Category 1}

(a) Conception and Design

Andrea Burri

(b) Acquisition of Data Andrea Burri

(c) Analysis and Interpretation of Data Andrea Burri; Ana Carvalheira

\section{Category 2}

(a) Drafting the Article Andrea Burri; Ana Carvalheira

(b) Revising It for Intellectual Content Andrea Burri; Ana Carvalheira

\section{Category 3}

(a) Final Approval of the Completed Article Andrea Burri; Ana Carvalheira

\section{REFERENCES}

1. Kinsey A, Pomeroy W, Martin C. Sexual behavior in the human male. Philadelphia: WB Saunders; 1948.
2. Kinsey A, Pomeroy W, Martin C, et al. Sexual behavior in the human female. Philadelphia: WB Saunders; 1953.

3. Rowan EL. The joy of self-pleasuring. New York: Prometheus Books; 2000.

4. Laqueur TW. Solitary sex: A cultural history of masturbation. Brooklyn, NY: Zone Books; 2003.

5. Jannini EA, Fisher WA, Bitzer J, et al. Controversies in sexual medicine: Is sex just fun? How sexual activity improves health. J Sex Med 2009;6:2640-2648.

6. Coleman E. Masturbation as a means of achieving sexual health. J Psychol Hum Sex 2003;14:5-16.

7. Carvalheira A, Leal I. Masturbation among women: Associated factors and sexual response in a Portuguese community sample. J Sex Marital Ther 2013;39:347-367.

8. Kaestle CE, Allen KR. The role of masturbation in healthy sexual development: Perceptions of young adults. Arch Sex Behav 2011;40:983-994.

9. Oliver MB, Hyde JS. Gender differences in sexuality: A metaanalysis. Psychol Bull 1993;114:29.

10. Leitenberg H, Detzer MJ, Srebnik D. Gender differences in masturbation and the relation of masturbation experience in preadolescence and/or early adolescence to sexual behavior and sexual adjustment in young adulthood. Arch Sex Behav 1993;22:87-98.

11. Hessellund $\mathrm{H}$. Masturbation and sexual fantasies in married couples. Arch Sex Behav 1976;5:133-147.

12. Gerressu M, Mercer CH, Graham CA, et al. Prevalence of masturbation and associated factors in a British national probability survey. Arch Sex Behav 2008;7:266-278.

13. Hatzichristou D, Rosen RC, Denogatis LR, et al. Recommendations for the clinical evaluation of men and women with sexual dysfunction. J Sex Med 2010;7:337-348.

14. Giraldi A, Rellini A, Pfaus JG, et al. Questionnaires for assessment of female sexual dysfunction: A review and proposal for a standardized screener. J Sex Med 2011;8:26812706.

15. Burri A, Porst H. Preliminary validation of a German version of the Sexual Complaints Screener for women in a female population sample. J Sex Med 2018;6:191-208.

16. Rosen RC, Brown C, Heiman J. The Female Sexual Function Index (FSFI): A multi-dimensional self-report instrument for the assessment of female sexual function. J Sex Marital Ther 2000;26:191-208.

17. Berner MM, Kriston L, Zahradnik HP, et al. Validity and reliability of the German Female Sexual Function Index (FSFI-D). Geburtshilfe Frauenheilkd 2004;64:293-303.

18. Hendrick SS. A generic measure of relationship satisfaction. J Marriage Fam 1988;50:93-98.

19. Muck PM, Hell B, Gosling SD. Construct validation of a short five-factor model instrument: A self-peer study on the German adaptation of the Ten-Item Personality Inventory (TIPI-G). Eur J Psychol 2007;23:166-175. 
20. Gosling SD, Rentfrow PJ, Swann WB. A very brief measure of the big five personality domains. J Res Personal 2003; 37:504-528.

21. Dinkel A. An evaluation of the German Relationship Assessment Scale. Swiss J Psychol 2005;64:259-263.

22. Pohlmann K, Thiel P, Joraschky P. Development and validation of the Dresden Body Image Questionnaire. In: Joraschky P, Lausberg H, Poöhlmann K, eds. Body-oriented diagnostics and psychotherapy in patients with eating disorders. Gießen: Psychosozial-Verlag; 2008. p. 57-72.

23. Lidster CA, Horsburgh ME. Masturbation-beyond myth and taboo. Nurs Forum 1994;29:18-27.

24. Ba'cak V, Stulhofer A. Masturbation among sexually active young women in Croatia: Associations with religiosity and pornography use. Int J Sex Health 2011;23:248-257.

25. McQuaid RJ, Mclnnis OA, Paric A, et al. Relations between plasma oxytocin and cortisol: The stress buffering role of social support. Neurobiol Stress 2016;30:52-60.

26. Magon N, Kalra S. The orgasmic history of oxytocin: Love, lust, and labor. Indian J Endocrinol Metab 2011;15:156-161.

27. Herbenick D, Bowling J, Fu TJ, et al. Sexual diversity in the United States: Results from a nationally representative probability sample of adult women and men. PLoS One 2017; 12:e0181198.

28. Bancroft J. Human sexuality and its problems. 3rd ed. Edinburgh, NY: Elsevier; 2009.

29. Berridge KC, Kringelbach ML. Pleasure systems in the brain. Neuron 2015;86:646-664.

30. Prause N. The human female orgasm: Critical evaluations of proposed psychological sequelae. Sex Rel Ther 2011;26:315328.

31. Harris JM, Cherkas LF, Kato BS, et al. Normal variations in personality are associated with coital orgasmic infrequency in heterosexual women: A population-based study. J Sex Med 2008;5:1177-1183.

32. Satinsky S, Reece M, Dennis B, et al. An assessment of body appreciation and its relationship to sexual function in women. Body Image 2012;9:137-144.

33. Randolph JF, Zheng $\mathrm{H}$, Avis NE, et al. Masturbation frequency and sexual function domains are associated with serum reproductive hormone levels across the menopausal transition. J Clin Endocrinol Metab 2015;100:258-266.

34. Wiederman MW. Volunteer bias in sexuality research using college student participants. J Sex Res 1999;36:59-66. 